\title{
AN ANALYTIC HIERARCHY PROCESS (AHP) MODEL TO ANTICIPATE LOGISTICS ORGANIZATION'S PREFERENCE FOR OPERATIONS RESEARCH (OR) TOOLS ADOPTION
}

\author{
Wan Fei Lai* \\ Faculty of Business and Information Sciences \\ UCSI University \\ Cheras, KL, Malaysia \\ E-mail: jefflai@ucsiuniversity.edu.my \\ Miang Hong Ngerng \\ Faculty of Business and Information Sciences \\ UCSI University \\ Cheras, KL, Malaysia \\ E-mail: ngerngmh@ucsiuniversity.edu.my \\ Min Yoong Ho \\ Faculty of Business and Information Sciences \\ UCSI University \\ Cheras, KL, Malaysia \\ E-mail: hmyoong@ucsiuniversity.edu.my
}

\begin{abstract}
Operation research (OR) has a remarkable impact in improving the efficiency of operations of many logistics organizations. Whether the logistics organizations adopt the operations research tools is always a serious decision making for the management due to the amount of investment can be significant from a firm prospective. The objective of this paper is to use an analytic hierarchy process (AHP) model to analyze the consideration for a logistics organization to adopt the operation research tools. The AHP model depicts the main criteria and sub-criteria that were considered by a logistics organization in a decision making on the adoption of operations research tools and management system. We proposed six main criteria, namely operations cost, benefits, penalty of making errors for not using the tools, human resource competency, effectiveness and organization's image. Each of theses criterion are operationalised into two sub-criteria based on researches from past literature and discussion with senior member of some organizations. Our findings seem to indicate that investment may not be the major issue in the decision, rather personnel competency and organization structure and workflow overhaul can be the main deterrents of the decision to adoption OR tools and management system. This understanding could help us in designing training to facilitate the adoption of OR tools and management system.
\end{abstract}

Keywords: analytic hierarchy process, operations research tools, logistics organization, selection criteria, OR adoption

\section{Introduction}

Adoption of OR tools are getting wider among the logistics organization. While industrial problems become more complex and involves tens of thousands of variable under consideration, the iterative

\footnotetext{
${ }^{*}$ Corresponding author
} 
solution of the OR tools find its potentials in the increasing computation power of the computers. The way the management of the logistics organization decides on which OR tools to adopt still remains interesting even though OR tools have been developed since the Second World War. Traditionally, cost may become the major factor in the decision of the OR tools adoption. However, many external factors are emerging and some of them become prominent factors in modern business practices. An analysis on the way logistics organization choose among different OR tools is therefore valuable in providing much needed answer to the question. However, past studies mostly focus on analysis of operational issues in manufacturing (Norman Gaither, 2007); opportunity for OR in supply chain management (Michael J. and W. C. Benton, 1997); and OR models in reverse logistics (M Fleischmann et al., 1997).

The objective of this paper is to perpetuate the adoption of the OR tools among the logistics organization by presenting an analytic hierarchy process (AHP) model which depicts the main criteria and sub-criteria, and the weight of these individual criteria, that were used by the logistics organization to choose the OR tools. Based on past research in the OR adoption in common business industry, we identified seven groups of main criteria, i.e. operations cost, benefits, human resource competency, effectiveness and organization's image. In the sections that follow, we review OR tools selection criteria, describe the research methodology, present the analysis results, and conclude the paper.

\section{Literature Review}

After rounds of preliminary discussion with retrospect of research findings from past literature, we have identified six criteria for consideration.

\subsection{Operational cost}

Numerous studies have attempted to explain the cost as the important consideration in decision making or new technology adoption. A previous study was carried out by Eichler et al. (2004) describing the emergence and development of the cost-effectiveness threshold in cost-effectiveness analysis. In the study, the threshold figure is defined as the cost per unit of health gain that to be analyzed for making resource-allocation decisions. There are more and more healthcare organizations identifying the issue of cost in decision making. Hence, they are adopting the cost-effective analysis as the important tool for them to allocate the health-care resources. Laupacis et al. (1992) also conducted the similar research in the past about the criteria of introducing the new technology or treatment in health care industry. They did the Comparison of two treatments, which are hemodialysis and myocardial infarction. The results shown that the total cost latter is relatively greater than the former with result of conducting the hemodialysis to the patients after the estimation of the cost and benefit. Utilization of hemodialysis to the patients was mainly due to the cost and its effectiveness. Therefore, we operationalize this criterion in our research by using "training cost of users" and "cost of time allowed for users to learn the software" as its sub-criteria.

\subsection{Benefits}

It is the universal agreement that the benefit is one of the important factors to new technology adoption. In the study by Hall and Khan (2003), the term of benefit was generally defined as the benefits that are obtained throughout the life of the adopted innovation. They highlighted the cost and benefits of the new technology will greatly affect its diffusion or even make contribution to the economic growth. Decisions of adopting a new technology are always the results from comparing the uncertain benefits and costs. Similarly, Pires and Aisbett (2003) showed that the sustainable productivity benefits including the operational and economic gains will lead to the decision of adopting technology and strategy in business and business markets. Lee (2009) also identified the perceived benefits as one of the major factor of internet banking adoption. The users can benefit from faster transaction speed and more information transparency resulting the adoption of online banking. Thus, we use two sub-criteria as indicator of this criterion. They are "cost reduction in long term operations" and "higher efficiency in current operations". 


\subsection{Capital Investment}

Sahay and Gupta (2003) studied the development of software selection criteria for supply chain solutions stating the cost of purchase software and hardware was one of the important criteria of software selection. In order to choose the appropriate software to have better supply chain solutions, many organizations need to take account of special equipment and annual cost, maintenance cost, hardware cost and etc. Since many OR tools are in the form of software packages, it is necessary to obtain these packages as careful allocation of capital investment may increase the productivity of the business organization, according to Gale (1982). Capital investment will consists of the cost of purchase of software and required hardware system as the sub-criteria in our study.

\subsection{Effectiveness of OR tools}

One of the main difficulty of a logistic management problem is about the uncertainty of the future. Some researcher such as Chian (2000) proposed models which are able to handle the stochastic aspect of logistics activities. Due to the historical ground of the development of mathematical theories in the operational research, the operations research theories are quite developed in modern days and the results of implementing the OR tools are effective. In addition, modern business entities evolve in the environments (Terreberry, 1968) and as the business entities grow, their operations become more complex and the use of the OR tools and the respective systems become prominent in the business activities. To operationalise this criterion, we use the following two sub-criteria:"reduction of errors made in decision making" and "faster decision made".

\subsection{Human resource competency in using OR tools}

One of the concerns in adopting a new system is the availability of the staff to operate the system. According to Becker (1996), human resource decisions are likely to have an important and unique influence on organizational performance. If existing staff is required to learn the system, learning process is inevitable and it contributes into additional expenses of the business entity. Besides, recruitment can be performed to take in new staff and again it contributes into additional expenses of the business entity. To further to review this criterion, "willingness of existing staff to learn a new system" and "availability of new candidate to use the OR system" are the two sub-criteria in this study.

\subsection{Company Image}

The subject of company image has attracted interest of industrial academics and practitioners for the last few decades. According to Dowling (1986), it requires intimate understanding on how the company images are formed and how to measure them to manage the company image well. Certain logistics and transport industries such as container terminal operations (Steenken et al., 2004) and air freight industry (Barnhart, 2003) adopts operational research algorithms to attract clients into their businesses. As the logistics and transport businesses grow, the companies find themselves indispensable to the adoption of operational research system and the potential clients may refer the company image to the adoption of the system of the operational research tools. Therefore, to indicate the concern of the criterion of company image, we use sub-criteria "OR as a tool to be adopted to follow the industrial practices" i.e. follow industrial practices to adopt OR system and "OR as a tool to brand the company image" i.e. company service quality match up with international companies that adopt OR system.

\section{Methodology}

Prior to the distribution of the questionnaires, the pilot questionnaires had been given to four persons who are working in managerial position in logistics companies to identify the possible selection main criteria, sub-criteria and alternatives. After that, we designed a questionnaire that displays the main criteria, sub- 
criteria and alternatives and then distributed out to the managerial staffs in logistic companies. They compared the relative importance and preference with respect to the main criteria, sub-criteria and alternatives with the scale ranging from 1 to 5 on both ends. The meaning of the scaling can be referred to Figure 1 below.

Eventually, we collected five questionnaires from different logistic companies. Four out of five respondents are from the companies with the employee number between 150 to 1000 whereas the employer number is below 150 for the left. To address the issue of exploring the criteria in choosing the operation research methods and the outcome of the alternatives, we performed Analytical Hierarchy Process (AHP) by using SuperDecisions software. There are three main components in the AHP model which is shown in Figure 1. It consists of goal, seven main criteria, two sub-criteria in each of the main criteria and two alternatives.

The analytic hierarchy process (AHP) is a useful and powerful method in decision making when one is encountered with a number of selection criteria and multiple-choice alternatives. In respect to this situation, it would be useful to first tell which selection criterion is more important than one another and then to work out which alternative is more likely. The AHP arranges criteria and alternatives in a hierarchical form, compares two criteria or alternatives in a pair, and calculates the priorities of individual criteria and alternatives (Saaty, 1997, 2003, 2006).

Table 1: Meaning of the fundamental scale of absolute numbers.

\begin{tabular}{|c|l|l|}
\hline $\begin{array}{c}\text { Intensity of } \\
\text { Importance }\end{array}$ & \multicolumn{1}{|c|}{ Definition } & \multicolumn{1}{c|}{ Explanation } \\
\hline 1 & Equal Importance & Two activities contribute equally to the objective \\
\hline 2 & $\begin{array}{l}\text { Weak or slight } \\
\text { importance }\end{array}$ & $\begin{array}{l}\text { Experience and judgment slightly favour one } \\
\text { activity over another }\end{array}$ \\
\hline 3 & Moderate importance & $\begin{array}{l}\text { Experience and judgment strongly favour one } \\
\text { activity over another }\end{array}$ \\
\hline 4 & Strong importance & $\begin{array}{l}\text { An activity is favoured very strongly over another; } \\
\text { its dominance demonstrated in practice }\end{array}$ \\
\hline 5 & $\begin{array}{l}\text { Extreme strong } \\
\text { importance }\end{array}$ & $\begin{array}{l}\text { The evidence favouring one activity over another is } \\
\text { of the highest possible order of affirmation }\end{array}$ \\
\hline
\end{tabular}

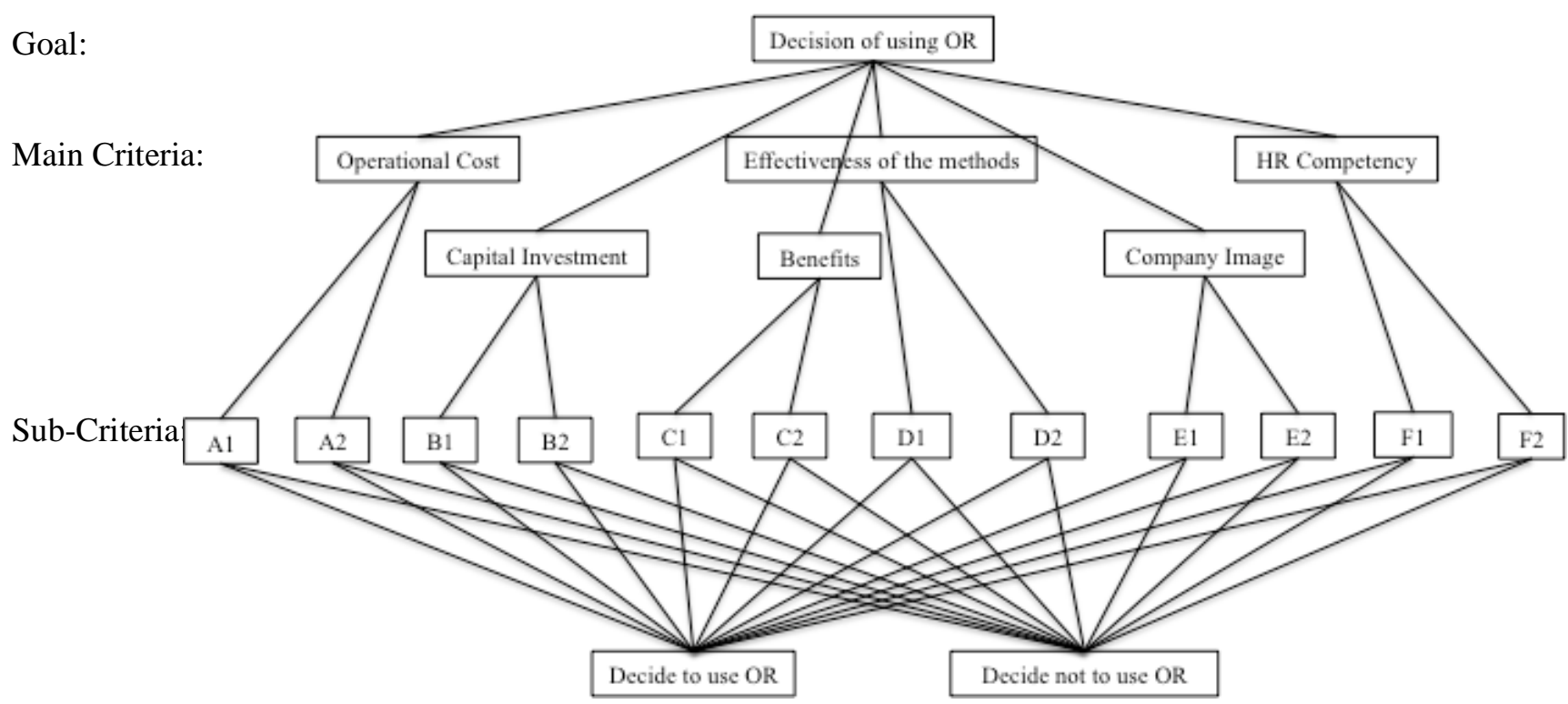


Alternative:

A1: Training cost of users

A2: Cost of time allowed for users to learn the software

B1: Cost of purchase of the software

B2: Cost of purchase of required hardware system (terminals + network system)

$\mathrm{C} 1$ : Cost reduction in long term operations

C2: Higher efficiency in current operations

D1: Reduction of errors made in decision making

D2: Faster decision made

E1: OR as a tool to be adopted to follow the industrial practices

E2: OR as a tool to brand the company image

F1: Willingness of existing staff to learn a new system

F2: Availability of new candidate to use the OR system

Figure 1. The AHP model

\section{Result and Discussion}

The result from the SuperDecisions software showed an acceptable inconsistency ratio of 0.10997. It indicates that the set of judgments by our respondents are consistent to be reliable according to the suggestions of Saaty (1980). Table 1- 8 showed the respective priorities of main criteria, sub-criteria and alternatives from the results of the pairwise comparison in the AHP model. It reveals the relative importance and preference between the criteria and alternatives.

Referring to Table 2 below, the respondents suggest that the company image was the top priorities of main criteria in choosing operational research method, followed by HR Competency, Effectiveness of the Methods, Capital Investment, Benefits and Operational Cost.

Table 2: Priorities of main criteria

\begin{tabular}{|l|l|l|}
\hline No. & Main Criteria & Priorities \\
\hline 1 & Company Image & 0.2198 \\
\hline 2 & HR Competency & 0.2023 \\
\hline 4 & Effectiveness of the Methods & 0.1964 \\
\hline 5 & Capital Investment & 0.1470 \\
\hline 6 & Benefits & 0.1402 \\
\hline 7 & Operational Cost & 0.0943 \\
\hline
\end{tabular}

Table 3 below shows the priorities of different sub-criteria in regards to its main criteria.

Table 3: Priorities of the sub-criteria

\begin{tabular}{|l|l|l|l|}
\hline No. & Main Criteria & Sub-Criteria & Priorities \\
\hline 1 & Company Image & OR as a tool to brand the company image & 0.7682 \\
\cline { 3 - 5 } & $\begin{array}{l}\text { OR as tool to be adopted to follow the industrial } \\
\text { practices }\end{array}$ & 0.2317 \\
\hline 2 & HR Competency & Availability of new candidate to use the OR & 0.5546 \\
\hline
\end{tabular}




\begin{tabular}{|l|l|l|l|}
\hline & & system & \\
\cline { 3 - 4 } & & Willingness of existing staff to learn a new system & 0.4453 \\
\hline 3 & $\begin{array}{l}\text { Effectiveness of } \\
\text { the Methods }\end{array}$ & Faster decision made & 0.8270 \\
\cline { 3 - 4 } & Reduction of errors made in decision making & 0.1729 \\
\hline 4 & $\begin{array}{l}\text { Capital } \\
\text { Investment }\end{array}$ & Cost of purchase of required hardware system & 0.7344 \\
\cline { 3 - 4 } & Benefits & Cost of purchase of the software & 0.2655 \\
\cline { 3 - 4 } & & Cost reduction in long term operations & 0.5973 \\
\hline 6 & $\begin{array}{l}\text { Operational } \\
\text { Cost }\end{array}$ & $\begin{array}{l}\text { Cost of time allowed for users to learn the } \\
\text { software }\end{array}$ & 0.4062 \\
\cline { 3 - 4 } & & Training cost of users & 0.7563 \\
\hline
\end{tabular}

Table 4 below represented the priorities of the alternatives. It showed that respondents will decide to use OR method with the priorities of 0.3617 , whereas decide not to use OR was 0.6383 . It indicated that the respondents decide to use OR was $56.66 \%$ as good as decide not to use OR.

Table 4: Priorities of alternatives

\begin{tabular}{|l|l|l|}
\hline Alternatives & Ideals & Priorities \\
\hline Decide to use OR & 0.5666 & 0.3617 \\
\hline Decide not to use OR & 1.0000 & 0.6383 \\
\hline
\end{tabular}

The AHP model shown in Figure 2 was the final model of the priorities of the main criteria, sub-criteria and alternatives.

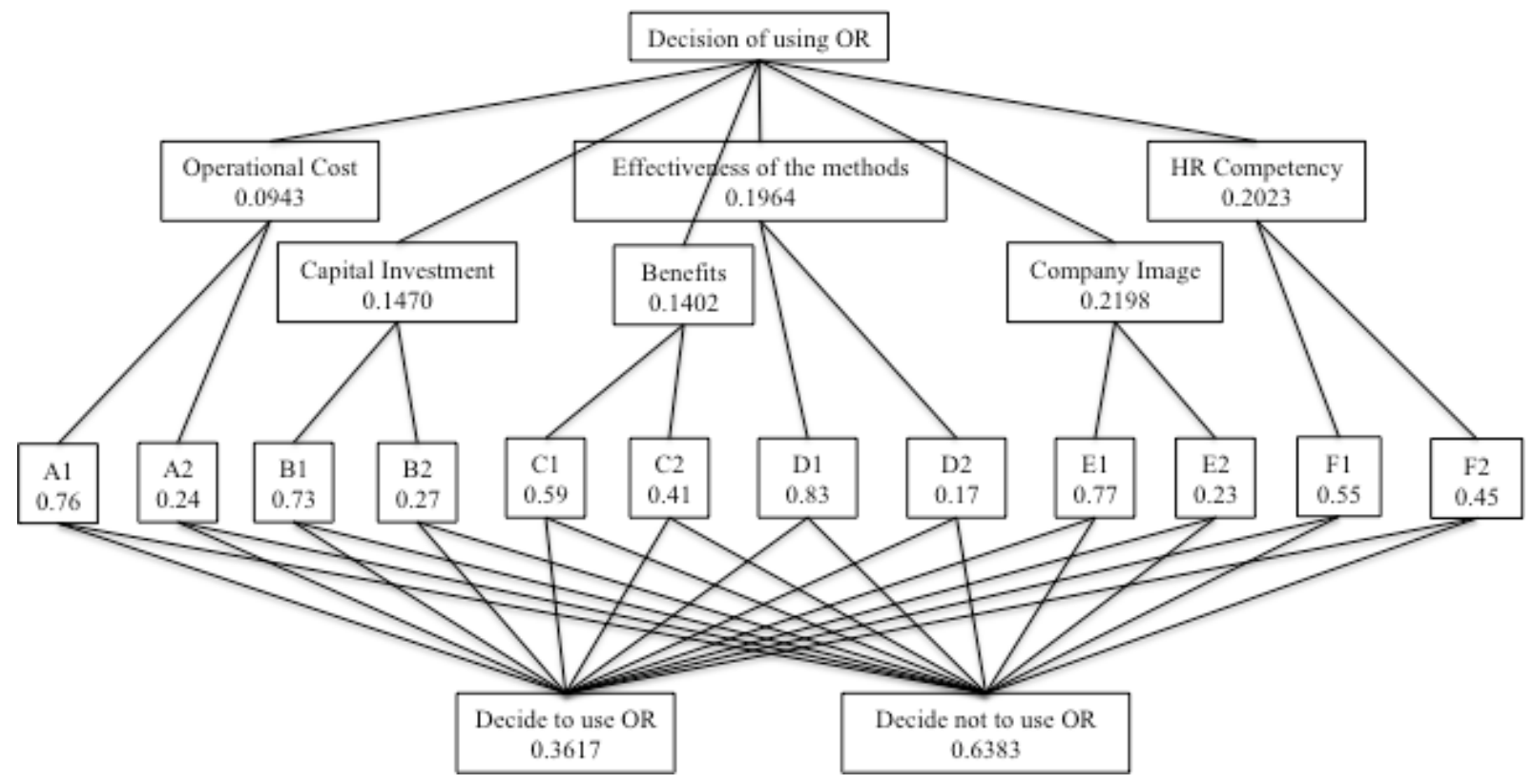

A1: Training cost of users

A2: Cost of time allowed for users to learn the software

B1: Cost of purchase of the software

B2: Cost of purchase of required hardware system (terminals + network system)

$\mathrm{C} 1$ : Cost reduction in long term operations

C2: Higher efficiency in current operations

D1: Reduction of errors made in decision making

D2: Faster decision made

E1: OR as a tool to be adopted to follow the industrial practices

E2: OR as a tool to brand the company image

F1: Willingness of existing staff to learn a new system

F2: Availability of new candidate to use the OR system 
Figure 2. Final AHP model

From the results above, the findings indicate that the respondents seem to place the attainment of company image as the top priority in the decision of OR tools adoption followed by HR competency, effectiveness of the methods. Factors like capital investment, benefits and operational cost deem as key consideration in technologies adoption by most literature are considered less significant in the decision for adoption. The results contradicted advocation of existing literature like Eichler et al. (2004), Laupacis et al. (1992) and Sahay and Gupta (2003) that put the operational cost and capital investment as the main concern. The seeming contradicting findings may not necessarily undermine validity of our study. As the amortized one-off capital investment required over the expected life span of the system can be closed to the annual cost reduction from the improved efficiency contributed by the new system. Hence the net off cost benefit from OR adoption can be negligible from company overall budgetary prospective. Whereas the training cost of personnel and subsequently remuneration to keep them working on the system may have a more lasting impact on the company costs and power structure so that the decision maker placed more weight on this issue. This result is in line with the findings from Steenken et al.(2004) and Barnhart (2003) describing the consideration of the company image to attract clients into the businesses. Human competency, which is ranked as second highest priority in the result, has the great influence to the organizational performance according to Becker (1996).

As for "company image" as a criterion in the decision making, it is indeed important as it can be an assurance to the firm's clients on the quality of the services provided by the firm. Such attainment may not be achieved without pain even though no explicit costs associated it. As the claim that the firm adopted OR tools and management system could also mean an overhaul on the logistic firm's major work processes to revolve around the OR tools incorporated management system. This is the reason why most of the firms interviewed considered company image as the main key criterion in the decision on adoption of OR techniques. Currently most of the small logistic companies may have issues in supporting a highly divisionalized workflow system structured around the OR incorporated management system, the capability of delivering the service quality and the consistency in supporting brand image. The respondents may recognize the importance of main criteria but failed to achieve and meet requirement $f$ the system and decided not to use OR tool with the priority of 0.6383 . This findings may mean there are works to be done in order the domestic industry to be inline with the management practices of their counter in more advanced economies.

\section{Conclusion}

Operation Research (OR) has been recognized as the key driver to make the better business decision and used in different industry aiming to enhance the business innovation and development. However, there are full of considerations in the OR tools adoption. The main purpose of this study is to investigate the priority of the criteria in the decision of the OR tools adoption. The major finding shows that the industry practitioners in the logistic companies have more concern on company image and human resource competency in operations research tools adoption. The main criteria have failed to achieve and meet their expectation with the result that they decide not to use OR tools with the priority of 0.6383 . This paper provides an avenue to identify the priorities of criteria of influencing the OR tools adoption and take stock the current level of penetration of the OR adoption in logistic industry. To further identify the structure 
among the criteria considered, we will apply Interpretative Structural Modeling (ISM) to study the interrelatedness of the criteria.

\section{REFERENCES}

Barnhart, C., Belobaba, P., \& Odoni, A. R. (2003). Applications of operations research in the air transport industry. Transportation science, 37(4), 368-391.

Becker, B., \& Gerhart, B. (1996). The impact of human resource management on organizational performance: Progress and prospects. Academy of management journal, 39(4), 779-801.

Dowling, G. R. (1986). Managing your corporate images. Industrial marketing management, 15(2), 109115.

Eichler, H.-G., Kong, S. X., Gerth, W. C., Mavros, P., \& Jönsson, B. (2004). Use of cost-effectiveness analysis in health-care resource allocation decision-making: how are cost-effectiveness thresholds expected to emerge? Value in Health, 7(5), 518-528.

Fleischmann, M., Bloemhof-Ruwaard, J. M., Dekker, R., Van Der Laan, E., Van Nunen, J. A., \& Van Wassenhove, L. N. (1997). Quantitative models for reverse logistics: A review. European journal of operational research, 103(1), 1-17.

Gaither, N. (1975). The adoption of operations research techniques by manufacturing organizations. Decision Sciences, 6(4), 797-813.

Gale. B. T. (1982). Can more capital buy productivity. Harvard business review, 58(4), 78-86.

Hall, B. H., \& Khan, B. (2003). Adoption of new technology. National Bureau of Economic Research. Retrieved from http://www.nber.org/papers/w9730

Laupacis, A., Feeny, D., Detsky, A. S., \& Tugwell, P. X. (1992). How attractive does a new technology have to be to warrant adoption and utilization? Tentative guidelines for using clinical and economic evaluations. CMAJ: Canadian Medical Association Journal, 146(4), 473.

Lee, M.-C. (2009). Factors influencing the adoption of internet banking: An integration of TAM and TPB with perceived risk and perceived benefit. Electronic Commerce Research and Applications, 8(3), 130141.

Maloni, M. J., \& Benton, W. C. (1997). Supply chain partnerships: opportunities for operations research. European Journal of Operational Research, 101(3), 419-429.

Pires, G. D., \& Aisbett, J. (2003). The relationship between technology adoption and strategy in businessto-business markets: the case of e-commerce. Industrial Marketing Management, 32(4), 291-300.

Saaty, T. L. (1997). That is not the analytic hierarchy process: what the AHP is and what it is not. Journal of Multi-Criteria Decision Analysis, 6(6), 324-335.

Saaty, T. L. (2003). Decision-making with the AHP: Why is the principal eigenvector necessary. European journal of operational research, 145(1), 85-91. 
Saaty, T. L. (2006). Rank from comparisons and from ratings in the analytic hierarchy/network processes. European Journal of Operational Research, 168(2), 557-570.

Sahay, B. S., \& Gupta, A. K. (2003). Development of software selection criteria for supply chain solutions. Industrial Management \& Data Systems, 103(2), 97-110.

Steenken, D., Voß, S., \& Stahlbock, R. (2004). Container terminal operation and operations research-a classification and literature review. OR spectrum, 26(1), 3-49.

Terreberry, S. (1968). The evolution of organizational environments. Administrative Science Quarterly, 590-613.

Yu, C.-S., \& Li, H.-L. (2000). A robust optimization model for stochastic logistic problems. International Journal of Production Economics, 64(1), 385-397. 